\title{
Editorial
}

\section{THE FALKLANDS CAMPAIGN}

"The tumult and the shouting dies;

The Captains and the Kings depart:

... Lest we forget - lest we forget!"

Rudyard Kipling

Although he wrote in another context, Kipling's words from his renowned Recessional hold a prophetic warning for the Army Medical Services and, more important for their masters, lest they forget the hard-learned medical lessons of the land battle for the Falklands. On many occasions in the history of warfare the lessons of earlier campaigns have had to be relearned anew and it is sad but salutary to confirm the validity of the truism that history teaches that we do not learn from history. The purpose of this Editorial is to stem the drift to oblivion of the object lessons adduced. As the drama and activity of the brief land campaign start to recede into the mists of memory it is important to collect and collate the medical information, to identify shortcomings as well as successes, and to define the doctrines on which future teaching policy may be based. To this end the five professors of the Royal Army Medical College, none of whom was a member of the Task Force, have been asked to write a brief and preliminary appraisal of the medical problems encountered in the areas of their particular specialism.

In such operations as the recapture of the Falklands the public gaze not unnaturally concentrates on the work of the surgeons, and certainly the rapid and effective treatment of surgical casualties is of paramount importance not only for the saving and conservation of manpower but also for the maintenance of morale among troops in the field. However, no one should doubt the significant contribution made by all the component parts of the Army Medical Services and amongst these perhaps the most relevant is preventive medicine. The effective mental and physical preparation of troops committed to battle in one of the most hostile environments known to man is clearly a key factor in determining a successful outcome.

The series of reviews that follow must be regarded as provisional and preliminary in terms of the opinions expressed. It may be that some of what is said now by the Professors will turn out to be wrong when analysed by the more scientific and critical appraisals that will follow, but that does not mean that these things should not be said. It is right that they should be said and discussed so that ultimately, truth will emerge.

\section{Preventive Medicine}

\section{by Col I P Crawford, GM, FFCM}

It is without question that our troops involged in the Falkland Islands campaign suffered from medical conditions which might be considered $\overrightarrow{p b e} \mathrm{e}-$ ventable. What we need now is to look at ?he conduct of the campaign and consider how we anticipated problems and how successful owe were in overcoming them. It is of particular impogrtance to identfy those areas where execution 11 short of intention and to seek reasons for the $\mathbb{R}$ crepancies.

In any campaign there are two types of cascalty, those that are the direct result of enemy actiono and those resulting from a hostile environment, the छatter encompassing not only the physical environmen But also the prevailing health circumstances.

It behoves us therefore to consider the enyirenment of the Falkland Islands and review the lifeath risks pertaining. We had available at the \&ilet a reasonable amount of information upon whiteh to base our appreciation. The presence if United Kingdom of senior medical and ottmer islanders helped in this task.

From the purely "medical" point of view appeared that the only conditions of note causing problems in the local population were upper rëspiratory tract infections, bronchitis and a small amount of tuberculosis; no exotica that one comid ascertain. Such complaints did not pose a direct threat to our troops but pointed to problems were likely to encounter.

The physical environment on the other hand fid pose problems. The South Atlantic in winter $\overline{\text { ळis }}$ no place to be by choice and a long sea voyage with worsening weather is not a happy prospect. Presuming that motion sickness had not taken great a toll of the Force, and there is not migh that can be done to reduce the incidence, we needed to know what conditions of weather and terrain would confront our troops on arrival at the Islands.

The answer, extremes of heat and cold apăhi, was the worst possible environment in which 9o survive irrespective of carrying out military activities. The climate wet, cold and extremely wind the terrain wet, boggy in places, rocky elsewhese, 
some small mountains, minimal roads or tracks and generally ground impassable to vehicular movement. Outside the main settlement no shelter to be found and no protection from the weather. In short hostile in the extreme. The one essential of which there was no shortage, indeed an excess, was water in its natural state.

With a population of the order of eighteen hundred and sanitation appropriate to local circumstances it was clear that the addition of the Task Force would overload the local system apart from any disruption caused by the presence of the enemy or by military action. The nature of the terrain in part dictating the style of warfare indicated that the troops would have to be self sufficient with regard to food and that individual ration packs would be the order of the day.

With these thoughts in mind what could be done to reduce the toll the 'environment' would exact upon the Task Force? For once, time, in a curious way, was on our side. The long journey to the South Atlantic made possible adequate preparation and training in terms of further education and practice in first aid, primary medical care, basic hygiene and instruction in the use of protective clothing. Time was also well spent in building upon the 'Fit to Fight' programme so that on arrival in the war zone the troops would be able to accomplish the extremely demanding operations required of them.

Was the appreciation of the situation accurate, did the preventive measures taken succeed in their aim and was there any oversight?

In general terms the measures outlined above, together with the enhanced state of fitness and training of the troops, helped to ensure the successful outcome. However, not all went well and in particular the climate took a more fearsome toll than was anticipated. The incidence of non-freezing cold injury to the feet, trench foot, was high and presented a continuous drain on manpower. Factors contributing to this incidence: firstly the unavoidable immersion during landing, continuous wet weather, boggy ground, river crossings and lack of shelter; secondly those possible avoidable inapropriate footwear (no marching boot was equal to the conditions), poor foot hygiene, no facilities for drying gear, and in some cases previous cold injury. In short, conditions were optimal for this debilitating condition and the incidence reflected it. In the event only a proportion of those affected came into medical care, many pressed on regardless. How much longer they could have continued is an open question which fortunately was not put to the test. Probably associated with good preparation on the voyage was a very low incidence of hypothermia; those concerned recovered quickly and did not require evacuation. In a campaign where if it was needed it had to be carried on the man, shortcomings in the equipment for load carriage rapidly came to the fore and in particular the excessive loads carried by many accelerated the onset of fatigue to an unacceptable degree.

During hostilities the main food supply was either the Arctic or the General Service 24 hour ration pack; a significant number of troops did not eat all their rations with a consequent loss of weight and possible loss of efficiency. Reasons given for this failure ranged from "unappetising" foods, shortage of time, nature of operations to lack of potable water with which to prepare the meal particularly the Arctic ration.

Supplies of appropriate clothing, always a problem in cold/wet conditions, were somewhat limited and drying of clothes was usually difficult if not impossible.

Such were the problems of the hostile environment; encounters with the enemy added two further stresses apart from direct weapon casualties. The first, noise induced hearing loss, was a hazarde to which all were exposed both during preparatory training and during operations. We shall not know. the magnitude of this injury for some time tocome. The other condition of note was gastro enteritis. During the campaign the incidence of gastroenteritis was of insignificant proportions but the disease began to make its presence felt with the ces sation of hostilities and the liberation of Port Stanley. This development, surprising to some, was probably due to the more widespread adoption of communal cooking, the gross contamination of all accommodation and surrounding areas by enemy troops, and damage sustained by the water supply plant, mains and sewage disposal system such as it was. Here as elsewhere the sterling efforts of the environmental health personnel saved the day.

In summary it can be said that provisional comment from the preventive medicine aspect is that there is room for improvement but that much of the effort directed by the Army Medical Services into improving the fitness of the soldier, his awareness of hostile environments; his training in first aid, and attempts to improve his equipment paid off in this campaign.

As a last word it must be added that it was fortunate that there was time on the voyage south to make good some of the deficiences in unit preparedness.

\section{Field Psychiatry \\ by Col P Abraham, FRCPsych}

It is difficult for those who, like the writer, did not take part in the land battle to recover the Falklands to realize how ferociously each engage- 
ment was fought. These encounters, and the battle of which they formed part, were mercifully curtailed.

Had they lasted longer the number of those whose inability to fight was not attributable to injury or sickness would have escalated alarmingly. The chief reason for this assertion is that the number of such battleshock cases is inexorably linked to the number of wounded, and as the fabric of the unit is eroded by casualties, both physical and psychological, so does it become harder for the remainder to sustain themselves and each other in the face of bombardment and bereavement. Fortunately the same arithmetic applied with even more force to the enemy.

In order to support this claim that the number of battleshock cases was about to achieve significant proportions it is necessary to show that the law linking the incidence of battleshock to the incidence of wounding did in fact hold in this particular force and that the number of stress reactions was rising.

The battalions under study are three of the finest fighting units to be found anywhere. Training is tough, cohesion tight, leadership strong. Motivation and morale were acknowledged to be good. Commanders held the initiative and understood well the need to ensure respite for their own troops while denying it to the enemy. It is chastening to record that the ratio of battleshock to wounded still amounted in each case to between five and ten per cent.

It may be argued that with single figure numbers it matters not militarily and little from the humanitarian point of view whether the cases were managed successfully or not. This overlooks the fact that changing any one of the favourable factors mentioned, including the shortness of the war and the limited number of wounded, would have dramatically altered the picture. With perhaps a third of the battalion out of action, whether or not a section or two of physically fit men get back to effective duty begins to matter. Furthermore, some of the casualties were key men, the successful return to their original role of any one of whom would have justified the precious place in the land force of a man whose skills were devoted to this task.

There were no such specialized medical personnel ashore. In addition communications were difficult, a situation compounded by the peculiar arrangements of the Geneva Convention whereby once a casualty reached a Hospital Ship he was forbidden to return to the war. These circumstances negated the fundamental principles of early forward intervention and rapid return to duty. In the Falklands, battleshock casualties who left their units did not return to active duty. It is probably also fair to say that some of those occurring within the battalions could have been better managed, even though some previous knowledge of the subject was hurriedly ame fied on the journey South. (One CO, to his crefit, even read carefully an article on the subject poblished in this Journal!)

Would there always be time to do this? It is contended that the management of psychologial problems in battle should be an integral part of First Aid Training of all medical personnel a⿳⺈. all junior leaders, officers and NCOs. It is furt reser contended that there should be a specialised pgesence forward with a field medical unit. The Israelis have recently proved yet again the efficiency ${ }_{o} f$ this policy in Lebanon, but only because they hæd organized and trained for it in peacetime.

If we do not adopt these twin measures we might not be so lucky next time.

\section{Medicine}

\section{by Brig M Brown, FRCP}

In his general preface to the History of the Second World War, Sir Arthur MacNalty ${ }^{1}$ emghassises the value of medical histories of war to regerd discoveries and progress in medicine and surge $y$ under the stimulus of warfare, to relate how poblems of medical administration in theatres of

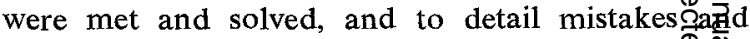
errors for the profit of those who come afterฉ

In the short Falkland Islands campaign the 通ain problems were those of logistics, and medigat, apart from cold injuries, there were no new op old diseases to diagnose and treat. The small hedigy civilian population meant there were no seposis demands on the physician, and the rapid repatriation of the Argentinian prisoners of war preventedo potential serious epidemic situation.

The emphasis lay on fitness, selection of persongel and the elimination of the unfit. The correct application of the Pulheems system and its Emplo ment Standards was again highlighted in those casses requiring evacuation for medical reasons. These included peptic ulcer, asthma, recurrent bronch and one case of hypertension. Too often in peastime the officer with well controllel hypertension on treatment is not downgraded. Selection of recruats with recent asthma or even on intermittment thera $\overrightarrow{\bar{y}}$ without proper screening tests still occurs.

In the Falkland Islands campaign the supply drugs was limited, there was no return to duty Oif case-evacuated to a hospital ship, and therefore there was no "line of communication" medical categos. Since the second World War there has been a n trend in therapy - the use of drugs to prevent lo $\mathrm{g} g$ term effects or relapses on such conditions as hypgetension, peptic ulcer, asthma and gout. In the Services, these people are otherwise fit, pass ther BFT, are often employed in highly specialised jobs, 
and have considerable service and experience. But as in the present campaign, medical drugs are not a first priority, and so regular therapy cannot be guaranteed. A review of this problem, the numbers involved, the effect on careers and the cost from wastage is needed in the light of these experiences. Certainly in the selection of recruits, or at their final medical, there is no place for any doubtful cases. Continued research into better selection methods and functional testing as in the Exercise Liability Test ${ }^{2}$ for asthma is essential.

In this short campaign there were no epidemics, no exotic diseases, and no major civilian problems as seen in the Second World War. The potential risk situation of the large number of prisoners of war, in a poor state of hygiene, with little accommodation was prevented by early repatriation. Should an epidemic have occurred, there were grave doubts expressed by the Consultant Physician, who arrived after the ceasefire, as to whether the required medical supplies would have been available. The medical drugs are limited in the Field ambulance and Field Hospital equipment for War. Research is required into the newer drugs, their shelf life, modular packing, and use in the field so that in the future, these are quickly available to meet specific circumstances and changing situations. Contrast the requirements, for example, of Camp Foxtrot in Zimbabwe, with a Field Ambulance in Jordan helping a United Nations force, and the Falkland Islands campaign.

To quote Major General Sir Henry Tidy "The traditional and essential function of military medical services is the maintenance of manpower in a state of fighting efficiency. Such function involves two separate factors, first the selection of the fit and suitable and elimination of the unfit, and secondly the prevention and treatment of disease. As physicians we have an important role in all three.

\section{Army Pathology}

\section{by Col J B Stewart FRCPath}

The Army Medical Services played a distinguished part in the Falklands Islands campaign and the courage and self-sacrifice of the Field Ambulances and Field Surgical Teams have been rightfully recognised and honoured. Less glamorous but nonetheless valiant contributions were made by other medical units. These contributed significantly to the success of the medical operation and added lustre to the reputation of the Corps. Army Pathology notably played its part throughout the hostilities and continues to provide an essential laboratory service to the Islands in the aftermath of the fighting. The operational readiness of the pathology services was well illustrated by the specialist sub-units, particulariy Army Blood Supply Depot (ABSD) and The David Bruce Laboratories (DBL) - units established during the Second World War for just such contingencies. On mobilisation of the Task Force DBL were able to issue large stocks of vaccine and smoothly gear their increased vaccine production to provide adequate emergency stocks. ABSD was heavily committed throughout the campaign and 1600 units of fresh blood were urgently collected and in four separate lots, each accompanied by a courier, delivered by air to Ascension Island. From Ascension individual deliveries were made by helicopter to passing hospital ships of the Task Force.

The blood was issued in new CPD-adenine preservative giving extended shelf life of 42 days (previously 28 days). The blood packs were transported in Ordnance Cardboard Polystyrene boxes. The latter containers and the increased blood preservation had both been the successful outcome of research and trials carried out at ABSD during the previous two years and both developments proved highly success 6 ful under field conditions. The entire blood supply operation demanded and received great co-operation ${ }^{+}$ from UKLF, local military units and the staff of ABSD. Signal traffic and the various logistic exer cises worked smoothly throughout and reflecteof realistic training in the past. The Commanding Officer ABSD records with pride the outstandingle loyal support of his civilian staff who worked longo hours collecting and processing blood; one all day session was completed the following morning af0500 hours. Before the Hercules transport aircraf: could land at Port Stanley blood was dropped by parachute on the disused end of the runway - and delivery successfully completed without loss of a single unit of blood! ABSD continues to supply the Falkland Islands from Aldershot with a regular monthly delivery of fresh blood by air.

In addition to the smooth blood supply organisation members of the Parachute Field Ambulance, who had undergone previous training at ABSD, instructed other personnel on the ships travelling down to the South Atlantic in blood collection and resuscitation. These men demonstrated splendid improvisation in blood storage on the ground and also supervised the bleeding of Argentine prisoners at the height of the fighting. This valuable contribution highlighted the additional role of ABSD, namely its commitment to regular training in resuscitation procedures.

A Laboratory Technician Class I accompanied 2 Field Hospital and at the end of hostilities was responsible for setting up a laboratory service in the small civilian hospital in Port Stanley in liaison with the local civilian general technician. A basic diagnostic service was quickly established using the 
fully serviceable field laboratory equipment. Many of the early problems involved basic field hygiene and public health checks, including control of water and milk supplies and highlighted the need for experienced Army technicians with broad general training in all laboratory disciplines - versatile all rounders. A senior laboratory technician is now posted to the Falklands on a five months rotation. The reference laboratories at Royal Army Medical College are the regular destination for specimens from outstations abroad and it was not long before interesting material, including surgical biopsies, cytological specimens and specimens for clinical chemistry and serological tests were arriving at Millbank. A steady stream of interesting case material arrives regularly from the Falklands. Consultant Pathologists have made the long journey to Port Stanley to conduct autopsies and review the laboratory facilities.

There are still many lessons to be learned from the Falklands conflict. The Army Pathology Service clearly demonstrated an excellent state of preparedness for its war role. The need for continuing energetic research and development in areas such as blood supply in war were underscored. In these days of ever threatening financial and staff cuts it is important that such vital tasks are fully recognised and given maximum support in terms of resources and skilled manpower in order that we remain prepared for any future conflict. The need for experienced all round technicians also vindicates the Amy's policy of a broad general training at RAM College. It is to be hoped that in the final analysis of all medical aspects of the Falklands campaign the contribution of Army Pathology will be fully realised and supported.

\section{Surgical Lessons \\ by Col R Scott FRCS}

Although Surgeons and Anaesthetists of the Army Medical Services have been continuously deployed with field surgical teams in support of military operations worldwide since the end of World War II, there has been no experience since then of the problems of surgical support of a Naval Task Force. Although surgical teams have often been situated some thousands of miles from a main base, the daily rate of casualties has seldom exceeded the capacity of the teams and casualty evacuation by air from the point of wounding to the field surgical team, and then rearward to a main hospital at base, has always been possible. The experience of the surgical teams in the Falklands conflict has emphasised the lessons learnt from previous experience but has also raised possibilities for improvement in the future.
Although the Task Force contained elements frop all three armed services, initial planning was the responsibility of the Royal Navy. With the necessitg for tri-service co-operation, it is essential that the Medical Officers of all three services understand fully the responsibilities and capabilities of the other two. Experience in the South Atlanti strengthened the case for tri-service co-operation if the education of Surgeons and Anaesthetists ang in the training exercises of forward surgical units. Difficult though they may be to achieve, the valum of realistic training exercises has been repeatedfo stressed by those involved in the South Atlantre operations, who emphasise the importance of fan iliarity with the equipment, the value of team trainings the necessity of training with their host medicsp units, and the importance of simple military fielc craft which can become as important for the sug vival of Surgeons and Anaesthetists as it is foo combatants.

Forward Anaesthetists must be completely fani iliar with field equipment and its potential. Anzes thetic experience based on the District General Ifos pital is insufficient to equip an Anaesthetist to fing tion effectively in an advanced surgical centre. प्रेe must be prepared to utilise his robust equipmen its full potential and be prepared to improvise os changing military situation may demand. The plest method of anaesthesia is often the safest and best in these circumstances. He must be suppost by competent, well-trained operating theatre tock nicians who have trained with the team.

The Surgeon also needs the support of a trained team of operating theatre technicians $\vec{w} / \overrightarrow{8}$ know their equipment, know their fieldcraft and hage trained with the other members of the tearg. Whereas at present the scales of equipment meart the need for going to war, they are capable \&f improvement and individual items must be repeated subjected to detailed scrutiny to effect these improve ments.

The Surgeons and Anaesthetists must be physica fit and psychologically capable of continuing function under extreme physical and emotion stress. The Surgeon must be capable of rapid degi sion and rapid surgery. He must be trained and ca able of operating on the head, chest and abdomein, as well as the limbs. Although limb injuries constitute the majority, injuries of the head and truak provide the most taxing surgical problems. If lives are to be saved by forward surgery, the militagy surgeon must be a truly general surgeon.

Rapid evacuation from point of wounding surgery is the most important factor in the saving of lives. Lives are also saved by effective first-aid and resuscitation, but in this campaign it is difficult in $\tilde{o}^{2}$ retrospective study to assess their value. The appoinds- 
ment of a consultant surgeon to the Force, with a specific duty to monitor treatment and assess its value at each point in the evacuation chain, could have provided much information that is unfortunately now lost. Regrettably, also lost is the opportunity to assess the impact of new weapon systems on personnel and the exact cause of a large number of superficial burns sustained by some soldiers in one notable incident.

The value of a specialised team for the treatment of burns in the base hospital, in this case a hospital ship, was proven. The Maxillo Facial Team was also usefully employed at base but it was interesting to note that other injured soldiers survived the long journey back to the United Kingdom for specialist treatment, without apparent ill-effect. The speed

\section{EXTRA EDITORIAL}

\section{Journal Style}

Discussions have been held recently with the Journal's printers and publishers, Messrs F Bailey \& Son of Dursley, Gloucestershire. As a result it has been decided, for an experimental period, to change the type face and format of the Journal's pages. The new appearance has the advantage of presenting more words in less space without loss of evacuation by air undoubtedly contributes to the successful management of specialised surgical problems.

The last, and possibly most important lesson, is that a professional army needs its own professional surgical teams as part of its medical support for operations worldwide.

\section{REFERENCES}

1 MacNulTY A S. History of the Second World War - Medicine and Pathology. HMSO London 1952

2 Carson J and Winfield $C$. Exercise Testing in Servicemen with Asthma. J $R$ Army Med Corps in press.

3 TIDY H. History of the Second World War Medicine and Pathology. HMSO London 1952.

of legibility, an achievement which will materially assist the Journal in its struggle against rising costso

Further changes and improvements are plannef and a new cover is being considered. The Editof $\mathrm{O}$ will welcome comments and suggestions from readerso in relation to both the present and contemplate ${ }^{2} c$ changes of face and appearance.
New Year Honours 1983

CBE Brig D S Paton, MBE, MB, ChB, FFCM

OBE Lt Col G S Welch, TD, RAMC(V).

\section{Academic achievements}

MRCP (UK) Capt M E H Kirkup, MB, ChB, RAMC. Maj J S Lloyd, MB, BS, RAMC. Capt N D Raby, MB, ChB, RAMC. Maj J W Simon, MRCS, LRCP, RAMC.

MRCPsych

DRCOG

Maj J D Mumford, MB, ChB,

Capt T O Jefferson, MD, RAMC. RAMC.

\section{Additional Qualifications}

Lt Col A J Warsap, MA, BM, BCh, MRCGP, has been elected to a Fellowship of the Royal College of General Practitioners.

\section{Honorary Consultants to the Army}

Mr R. A Williams, MA, MB, BCh, FRCS(Ed) DLO, was appointed Honorary Consultant in Otorhinolaryngology to the Army; with effect from 26 September 1982.

Dr A D M Bryceson, MD, FRCP, DTM\&H, was appointed Honorary Consultant in Tropical Diseases to the Army, with effect from 1 September 1982.

Dr M M Black, MB, BS, FRCP, was appointed Honorary Consultant in Dermatology to the Army, with effect from 8 September 1982.

Mr A Wallace, MB, FRCS, was appointed Honorary Consultant in Plastic Surgery to the Army, with effect from 1 January 1983.

\section{Honorary Consultant}

Mr. J N G Evans, MB, BS, FRCS, DLO, was appointed Honorary Consultant in Ortorhinolaryngology to the Queen Elizabeth Military Hospital, Woolwich, with effect from 26 September 1982. 